\title{
The prevalence of low vision and blindness in Canada
}

DAL Maberley ${ }^{1}$, H Hollands², J Chuo ${ }^{2}$, G Tam¹, J Konkal2,3,4,5, M Roesch ${ }^{6,7}$, A Veselinovic, $M$ Witzigmann ${ }^{1}$ and $K$ Bassett ${ }^{2}$

\begin{abstract}
Purpose The purpose of this study was to ascertain the prevalence and primary causes of visual impairment in a representative Canadian population.

Methods We reviewed a representative
\end{abstract} sample of patients who attended ophthalmologists' offices in a medium-sized Canadian city between 1996 and 2001 in order to estimate the prevalence of visual impairment. Demographic data, visual diagnoses, best-corrected visual acuities (BCVA), and visual field information were recorded. Visual status was categorized based on accepted World Health Organization (WHO) and North American criteria. Population data were obtained from the Canadian census.

Results The prevalence of low vision and blindness in our population was 35.6 and 3.8 per 10000 individuals, according to the WHO classification, and 71.2 and 23.6 per 10000 individuals, using the North American definition. Among individuals with some vision loss (vision worse than 20/40), cataract and visual pathway disease were the most common causes, together accounting for $40 \%$ of visual impairment. Age-related macular degeneration and other retinal diseases were the next most common causes of vision loss. Diabetic retinopathy and glaucoma were less frequently encountered as causes of visual impairment. Conclusion The overall prevalence of low vision and blindness in Canada are in keeping with data from large population-based studies from other developed nations. Cataract, visual pathway disease, and macular degeneration are the leading causes of visual impairment. These results are important for enhancing our understanding of the scope of vision health in Canada and may direct future health planning and cost-utilization research.
Eye (2006) 20, 341-346. doi:10.1038/sj.eye.6701879; published online 20 May 2005

Keywords: prevalence; blindness; visual disability; low vision; Canada; visual impairment

\section{Introduction}

Blindness is an important health care issue that exacts both economic and social costs. However, individuals with blindness only represent a small fraction of those with visual impairment. Reduced visual function that does not meet criteria for a definition of blindness is termed 'Low Vision'. The ageing of Canada's population and workforce, coupled with the increased visual demands of our modern culture, will increase the impact of low vision and blindness on our society in the coming decades.

Epidemiologic data about the causes and prevalence of low vision and blindness in Canada are weak. ${ }^{1,2}$ No population-based studies have evaluated the ocular health of Canadians in a representative population. Such studies would accurately define the present state of visual loss and blindness in Canada but are known to be expensive and time-consuming to carry-out. Best estimates of visual loss and blindness in Canada come from the 2001 Participation and Activity Limitation Survey (PALS) and the Canadian National Institute for the Blind (CNIB) registry.

The 2001 PALS survey found that $2.5 \%$ (594350 individuals) of Canadians had 'difficulty seeing ordinary newsprint or clearly seeing the face of someone from $4 \mathrm{~m}^{\prime} .^{3}$ In 2001, the CNIB registry classified 0.35\% (105000 individuals) of the Canadian population as visually disabled. ${ }^{4}$ These data are limited by lack of diagnostic and visual acuity coding
${ }^{1}$ Faculty of Medicine, University of British Columbia, Vancouver, BC Canada

${ }^{2}$ Department of Ophthalmology, University of British Columbia, Vancouver, BC, Canada

${ }^{3}$ Faculty of Medicine, University of British Columbia, Vancouver, BC, Canada

${ }^{4}$ Department of Ophthalmology, University of Northern British Columbia, Vancouver, BC, Canada

${ }^{5}$ Faculty of Medicine, University of Northern British Columbia, Vancouver, BC, Canada

${ }^{6}$ Faculty of Family Medicine, University of British Columbia, Vancouver, BC, Canada

${ }^{7}$ Faculty of Family Medicine, University of Northern British Columbia,

Vancouver, BC, Canada

Correspondence: DAL Maberley, 2550 Willow St., Vancouver, BC V5Z 3N9, Canada

Tel: + 1604875 4599; Fax: + 16048754699 .

E-mail: dmaberle@ vanhosp.bc.ca

Received: 29 October 2004 Accepted in revised form: 15 February 2005 Published online: 20 May 2005 
standards and by the voluntary nature of participation. Thus, disease-specific prevalence figures are not available from any prior study in Canada. Accurate visual impairment prevalence data is essential to (1) understand the present state of vision health in Canada and (2) to help direct public policy and resources towards the principal vision problems in Canada.

This paper provides an evaluation of the prevalence and causes of low vision and blindness in a mid-sized Canadian city - Prince George, British Columbia. Agestandardization of this data to the Canadian population provides the first national estimate of the prevalence of low vision and blindness in Canada.

\section{Materials and methods}

Prince George is a community of 85000 persons located in North-Central British Columbia. It is the primary referral centre for tertiary medical care in Northern British Columbia. Prince George is quite isolated and it would be unexpected for any resident to receive primary eye care outside of the community. The nearest city with an ophthalmologist is over $500 \mathrm{~km}$ away. Three ophthalmologists provide ophthalmic care for the region and all perform surgery. There is similar access to general medical and surgical ophthalmic services in Prince George compared with the rest of BC.

In order to determine the prevalence of blindness and low vision in Prince George, a sampling from all ophthalmic charts in the community was performed in August 2003. The three ophthalmologists participating in this study were the only physicians to practice ophthalmology in Prince George during the study period. Optometrists in British Columbia do not presently have access to therapeutic agents and, as such, we assumed that individuals with significant ocular pathology would be seen by one of the local ophthalmologists at least once during the study period.
A 5-year study period was chosen to coincide with the intercensus interval of the Canadian Census (June 1, 1996 and June 1, 2001). Any patient seen by a Prince George ophthalmologist during this period was eligible for inclusion. In order for a chart to be included in the study, the first three letters of the subject's postal code had to be part of the census definition for Prince George (postal codes: V2 K, V2L, V2 M, V2N), and the patient had to have been examined at least once during the study period. The best-corrected visual acuity and field tests from the eye examination closest to, but not after, June 2001 were used for the primary analyses.

Low vision and blindness were defined according to the World Health Organization (WHO) and North American criteria for the better-seeing eye (Table 1). Causes of visual loss and visual field interpretation for each patient were ascertained through chart review by an independent ophthalmologist (who did not have patients in the study). The causes of vision loss for each eye was recorded, but we classified visual disability by the cause of vision-loss in the better-seeing eye. If the cause of vision loss was unclear, a second ophthalmologist (the patient's ophthalmologist) was consulted and a decision regarding cause of vision loss was made via a consensus decision. If there was more than one potential cause of vision loss in the better-seeing eye, the primary reason for the visual loss was left to the chart reviewers' discretion. Vision loss was categorized into one of nine groups based on CNIB categories (see Table 3).

A sample size calculation performed $a$ priori showed that approximately 900 eligible charts were needed to obtain an estimate of prevalence with an absolute confidence interval of less than $\pm 3 \%$.

A pilot study of 100 consecutive charts were reviewed at each office to determine the sampling interval. In all three offices charts were filed alphabetically. First, the proportion of eligible charts based on postal code and date of clinic visit was determined (eg in one office $60 \%$

Table 1 Categorizations of visual loss based on the better seeing eye

\begin{tabular}{|c|c|c|c|}
\hline \multicolumn{2}{|c|}{ World Health Organization } & \multicolumn{2}{|c|}{ North America } \\
\hline Category & Definition & Category & Definition \\
\hline 0 - Normal vision & $20 / 25$ or better & Not impaired & Better than or equal to $20 / 40$ \\
\hline \multirow[t]{2}{*}{0 - Near normal vision } & $20 / 30-20 / 60$ & & \\
\hline & & Low vision & $\begin{array}{l}\text { Worse than } 20 / 40 \\
\text { but better than } 20 / 200\end{array}$ \\
\hline 1-Moderate low vision & $20 / 70-20 / 160$ & & \\
\hline 2 -Severe low vision & $20 / 200-20 / 400$ & Blind & $20 / 200$ or worse \\
\hline 3 -Profound vision & $20 / 500-20 / 1000$ or & & \\
\hline loss (blindness) & visual field $<10 \overline{\text { degrees }}$ & & \\
\hline 4 - Near total vision & $<20 / 1000$ or visual & & \\
\hline loss (blindness) & field $<5$ degrees & & \\
\hline 5-Total vision loss (blindness) & No light perception & & \\
\hline
\end{tabular}


of the 100 pilot charts pulled were eligible for the study). Second, a density extrapolation was used to estimate the eligible number of patients in each office and in total (average number of charts in a cabinet row times the proportion of eligible charts times the number of cabinet rows). Third, a sampling interval was determined (ie 'pull' one out of every $x$ charts in each office) such that we would include approximately 900 eligible charts (our a priori sample size). This sampling interval was calculated such that the number of charts reviewed at each office was in proportion to the estimated size of each physician's practice.

The proportion of our office sample defined as low vision or blind was used to estimate the number of low vision or blind patients in Prince George. The prevalence of visual impairment was determined by extrapolating the chart sample to the size of each clinical practice and, subsequently, to the population of Prince George (using 2001 Canadian Census Data). ${ }^{5}$ These data were then directly standardized to the Canadian population using the 2001 Census data. Confidence intervals were calculated using the exact method when describing the causes of visual disability and the distribution of visual disability. However, confidence intervals were not calculated for our prevalence estimates since the numerators of the prevalence figures were extrapolated from the chart review - the denominator coming from the Statistics Canada Census data for the entire Prince George population.

\section{Results}

We evaluated 2466 charts, of which 962 subjects were eligible for inclusion. No data were missing. The mean age of subjects was 51.4 years $(S D=22.3)$. In all, 24 patients $(2.5 \%)$ were less than 6 years old and $12.2 \%$ were under 20 years. A total of $13 \%$ of the sample was between the ages of 75 and 84 years and 3.3\% were over 84 years old. In all, $56 \%$ of the sample was female. This was significantly higher than the proportion of females in Prince George (49.6\%; $P<0.005)$.

In all, $81 \%$ (95\%CI: $78.2-83.2 \%)$ and $95.5 \%(95 \% \mathrm{CI}$ : 93.9-96.7\%) of the 962 patients in the sample had normal vision based on the WHO and North American classification, respectively. A total of $17 \%$ (95\%CI: 15.0 $19.9 \%$ ) of the sample had near-normal vision based on the WHO classification system. Table 2 shows the agespecific prevalence of visual disability in Prince George along with the absolute number of subjects in each category. Older age was significantly associated with low vision and blindness based on both vision impairment definitions ( $\chi^{2}$ for linearity, $P<0.005$ ). Female gender was

Table 2 Age-specific prevalence of blindness and low vision in prince george, BC

\begin{tabular}{|c|c|c|c|}
\hline \multirow[t]{3}{*}{ Age (years) } & Low vision and blindness & Low vision only & Blindness only \\
\hline & \multicolumn{2}{|c|}{ WHO Classification } & \\
\hline & $\begin{array}{c}\text { Prevalence per } 10000 \\
\text { (based on } 17 \text { of } 962 \text { subjects) }\end{array}$ & $\begin{array}{c}\text { Prevalence per } 10000 \\
\text { (based on } 15 \text { of } 962 \text { subjects) }\end{array}$ & $\begin{array}{c}\text { Prevalence per } 10000 \\
\text { (based on two of } 962 \text { subjects) }\end{array}$ \\
\hline $0-19$ & 4.25 & 4.25 & 0.00 \\
\hline $20-44$ & 6.57 & 6.57 & 0.00 \\
\hline $45-64$ & 5.17 & 0.00 & 5.17 \\
\hline $65-74$ & 52.41 & 52.41 & 0.00 \\
\hline $75-84$ & 416.15 & 356.70 & 59.45 \\
\hline $85+$ & 903.64 & 903.64 & 0.00 \\
\hline Total $^{\mathrm{a}}$ & 21.46 & 18.93 & 2.52 \\
\hline \multirow[t]{2}{*}{ Age (years) } & \multicolumn{2}{|c|}{ North American classification } & \\
\hline & $\begin{array}{c}\text { Prevalence per } 10000 \\
\text { (based on } 43 \text { of } 962 \text { subjects) }\end{array}$ & $\begin{array}{c}\text { Prevalence per } 10000 \\
\text { (based on } 31 \text { of } 962 \text { subjects) }\end{array}$ & $\begin{array}{c}\text { Prevalence per } 10000 \\
\text { (based on } 12 \text { of } 962 \text { subjects) }\end{array}$ \\
\hline 0-19 & 17.00 & 12.75 & 4.25 \\
\hline $20-44$ & 13.15 & 0.00 & 13.15 \\
\hline $45-64$ & 10.34 & 5.17 & 5.17 \\
\hline $65-74$ & 262.05 & 235.84 & 26.20 \\
\hline $75-84$ & 891.75 & 772.85 & 118.90 \\
\hline $85+$ & 1807.29 & 1129.55 & 677.73 \\
\hline Total $^{\mathrm{a}}$ & 54.27 & 39.13 & 15.15 \\
\hline
\end{tabular}

${ }^{a}$ Not age-standardized to the Canadian population. 
associated with higher degrees of vision loss $\left(\chi^{2}, P=0.04\right)$ also.

Prince George has a younger population than the Canadian average with roughly half the national percentage of individuals over 65 years of age. For this reason, the prevalence of low vision and blindness were age-standardized to the Canadian population. Based on the WHO classification, visual impairment was present in 39.4 per 10000 individuals. The age-standardized prevalence of low vision and blindness, respectively, was 35.6 and 3.8 per 10000 .

The age-standardized prevalence of visual impairment (including low vision and blindness) based on the North American definition was 94.8 per 10000 Canadian persons; the age-standardized prevalence of low vision and blindness, respectively, was 71.2 and 23.6 per 10000 Canadian persons.

The causes of low vision based on WHO and North American criteria are shown in Tables 3 and 4. According to the WHO definitions, cataract was the leading cause of low vision and blindness (29.9\% of cases). Age-related macular degeneration (13\%) was the second most common cause, followed by visual pathway $(12 \%)$ and other retinal diseases $(12 \%)$. Corneal disease, glaucoma, diabetic retinopathy, and refractive error were less common causes of vision loss.

Our figures were compared to the CNIB registry for Prince George to determine the percentage of visually disabled persons registered with the CNIB. The CNIB is accessible locally through the regional CNIB office in Prince George. In total, 15 of the 962 subjects were registered with the CNIB as of July 2001. Of these 15 individuals, 11 had their correct clinical diagnosis coded by the CNIB. Using the North American definition of blindness, only $33.3 \%$ (four of 12) of blind individuals and $19.4 \%$ (six of 31) of individuals with low vision were registered.

\section{Discussion}

To our knowledge no previous Canadian study has provided prevalence data on low vision and blindness based on actual clinical data. Thus, this is the first study to present such data in a representative Canadian population.

Table 3 Causes of visual loss based on the WHO definition ${ }^{\mathrm{a}}$

\begin{tabular}{|c|c|c|c|c|c|c|}
\hline \multirow[t]{2}{*}{ Cause of visual loss } & \multicolumn{2}{|c|}{ Not normal vision ${ }^{\mathrm{b}}(\mathrm{n}=184)$} & \multicolumn{2}{|c|}{ Near normal vision $(\mathrm{n}=167)$} & \multicolumn{2}{|c|}{ Low vision $(\mathrm{n}=15)$} \\
\hline & 'n' & Percentage (95\% CI) & 'n' & Percentage (95\% CI) & 'n' & Percentage $(95 \% \mathrm{CI})$ \\
\hline Age-related macular degeneration (ARMD) & 24 & $13.0(8.69-18.9)$ & 22 & $13.2(8.62-19.5)$ & 2 & $13.3(2.3-41.6)$ \\
\hline Diabetic retinopathy & 12 & $6.52(3.57-11.4)$ & 11 & $6.6(3.50-11.7)$ & 1 & $6.7(.35-33.9)$ \\
\hline Other retinal causes & 22 & $11.95(7.81-17.7)$ & 18 & $10.8(6.68-16.7)$ & 2 & $13.3(2.3-41.6)$ \\
\hline Glaucoma & 5 & $2.71(1.00-6.57)$ & 4 & $2.4(0.77-6.40)$ & 1 & $6.7(0.35-33.9)$ \\
\hline Visual pathway & 22 & $11.95(7.81-17.7)$ & 20 & $12.0(7.64-18.1)$ & 2 & $13.3(2.3-41.6)$ \\
\hline Cataract and cataract complications & 55 & $29.9(23.5-37.1)$ & 52 & $31.1(24.3-38.8)$ & 3 & $20.0(5.31-48.6)$ \\
\hline Cornea/conjunctiva & 21 & $11.41(7.36-17.1)$ & 20 & $12.0(7.64-18.1)$ & 1 & $6.7(.35-33.9)$ \\
\hline Refractive & 14 & $7.61(4.37-12.7)$ & 14 & $8.4(4.83-13.93)$ & 0 & 0 \\
\hline Other (iris, trauma, lid) & 9 & $4.89(2.40-9.37)$ & 6 & $3.6(1.46-8.00)$ & 3 & $20.0(5.31-48.6)$ \\
\hline
\end{tabular}

'The two blind patients had blindness caused by 'other retinal causes'.

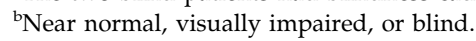

Table 4 Causes of vision loss based on the North American definition

\begin{tabular}{|c|c|c|c|c|c|c|}
\hline \multirow[t]{2}{*}{ Cause of visual loss } & \multicolumn{2}{|c|}{ Blind or visually impaired $(\mathrm{n}=43)$} & \multicolumn{2}{|c|}{ Visually impaired $(\mathrm{n}=31)$} & \multicolumn{2}{|r|}{ Blind $(\mathrm{n}=12)$} \\
\hline & 'n' & Percentage (95\% CI) & 'n' & Percentage $(95 \% \mathrm{CI})$ & 'n' & Percentage $(95 \% \mathrm{CI})$ \\
\hline Age-related macular degeneration (ARMD) & 7 & $16.3(7.32-31.3)$ & 5 & $16.1(6.09-34.5)$ & 2 & $16.6(2.94-49.1)$ \\
\hline Diabetic retinopathy & 3 & $7.0(1.81-20.1)$ & 3 & $9.7(2.53-26.9)$ & & \\
\hline Other retinal causes & 7 & $16.3(7.32-31.3)$ & 5 & $16.1(6.09-34.5)$ & 2 & $16.6(2.94-49.1)$ \\
\hline Glaucoma & 3 & $7.0(1.81-20.1)$ & 2 & $6.5(1.12-22.8)$ & 1 & $8.33(0.43-40.2)$ \\
\hline Visual pathway & 8 & $18.6(8.92-33.9)$ & 5 & $16.1(6.09-34.5)$ & 3 & $25.0(6.69-57.1)$ \\
\hline Cataract and cataract complications & 8 & $18.6(8.92-33.9)$ & 6 & $19.4(8.12-38.0)$ & 2 & $16.6(2.94-49.1)$ \\
\hline Cornea/conjunctiva & 2 & $4.7(0.81-17.0)$ & 2 & $6.5(1.12-22.8)$ & 0 & 0 \\
\hline Refractive & 2 & $4.7(0.81-17.0)$ & 2 & $6.5(1.12-22.8)$ & 0 & 0 \\
\hline Other (iris, trauma, lid) & 3 & $7.0(1.81-20.1)$ & 1 & $3.2(.16-18.5)$ & 2 & $16.6(2.94-49.1)$ \\
\hline
\end{tabular}


Table 5 Comparative prevalence figures for visual disability in developed nations worldwide (North American Definition of Blindness)

\begin{tabular}{|c|c|c|c|c|}
\hline Place of survey & Date of study & Age range comparison & Definition of visual disability & Prevalence (\%) \\
\hline \multirow[t]{2}{*}{ Baltimore, MD, USA ${ }^{6}$} & 1990 & $70-79$ & $\leq 20 / 40$ to $>20 / 200$ & 7.14 \\
\hline & & $70-79$ & $\leq 20 / 200$ & 0.47 \\
\hline \multirow[t]{2}{*}{ Beaver Dam, WI, USA ${ }^{7}$} & 1991 & $65-74$ & $\leq 20 / 40$ to $>20 / 200$ & 4.70 \\
\hline & & $65-84$ & $\leq 20 / 200$ & 0.53 \\
\hline \multirow[t]{3}{*}{ Blue Mountains, NSW, Australia ${ }^{8}$} & 1996 & $65-74$ & $\leq 20 / 40$ to $>20 / 200$ & 2.10 \\
\hline & & $49+$ & $\leq 20 / 200$ & 0.27 \\
\hline & & $65-84$ & $\leq 20 / 200$ & 0.53 \\
\hline \multirow[t]{3}{*}{ Rotterdam, Netherlands ${ }^{9}$} & 1998 & $65-74$ & $<20 / 40$ to $>20 / 200$ & 0.83 \\
\hline & & $55+$ & $\leq 20 / 200$ & 0.47 \\
\hline & & $65-85$ & $\leq 20 / 200$ & 0.53 \\
\hline \multirow[t]{2}{*}{ Copenhagen, Denmark ${ }^{10,11}$} & 2001 & $65-75$ & $<20 / 40$ to $>20 / 200$ & 2.11 \\
\hline & & $65-84$ & $\leq 20 / 200$ & 0.53 \\
\hline \multicolumn{5}{|l|}{ Present study } \\
\hline \multirow[t]{4}{*}{ Prince George, $\quad$ BC } & 2003 & $65-74$ & $<20 / 40$ to $<20 / 200$ & 2.36 \\
\hline & & $45+$ & $\leq 20 / 200$ & 0.27 \\
\hline & & $55+$ & $\leq 20 / 200$ & 0.46 \\
\hline & & $65-84$ & $\leq 20 / 200$ & 0.54 \\
\hline
\end{tabular}

Eye care in Canada is typically administered in the community setting and, as such, prevalence evaluations of blindness and low vision cannot be gleaned from hospital or institutional databases. Furthermore, the diagnostic codes that are submitted to Provincial Medical Service Plans (for billing purposes) vary tremendously in detail and accuracy. To ensure precise clinical diagnoses, bestcorrected visual acuities, and visual field data for our prevalence evaluation (in the absence of a large populationbased study) we believed it was essential to evaluate the medical records of practicing ophthalmologists.

By choosing to not include subjects from optometric or family physician offices, patients with visual disabilities could have been missed if they were managed solely by these care providers. Nonetheless, we believe it is likely that most individuals with chronic ocular pathology would have seen one of the Prince George ophthalmologists at some point in the 5-year study interval. Blind people with stable ocular status, however, could be underrepresented by our sampling methodology. In addition, low vision among the oldest age groups may also be under-represented due to comorbidities and/or the lack of awareness of slowly progressing eye disease. As a result, the prevalence data are a conservative estimate of the problem of visual impairment in Prince George and Canada.

The specific causes of vision loss identified within our Prince George sample are not entirely in keeping with the common diagnoses responsible for CNIB registration or other prevalence studies. While cataract and age-related macular degeneration are well represented in the Prince George population, visual pathway disease was more prevalent than might have been expected and diabetic retinopathy was less commonly noted. These findings may be related to the relatively young age of the population in question or to the possibility - as mentioned above - that patients with longstanding, stable ocular conditions such as ARMD may be underrepresented in the study sample. Interestingly, few of the people who might have benefited from low vision rehabilitation services were registered with the CNIB.

While it is problematic to compare our study's methodology to large population-based projects from other developed countries, we found the blindness and low vision prevalence estimates for Prince George to be quite similar. Table 5 shows that our prevalence estimates are comparable to studies from Australia, the United States, and Europe.

In conclusion, this is the first paper to estimate the prevalence of visual disability in Canada using accurate diagnostic and visual acuity data. Using the North American definition of blindness and low vision, approximately $1 \%$ of the population was noted to have a visual impairment. Low vision was estimated to be three times as common as blindness. As expected, increasing age was significantly associated with low vision and blindness.

\section{Acknowledgements}

Financial support: CNIB EA Baker Grant. Meeting presentation: UBC Department of Ophthalmology Annual Research Day May 2004. 


\section{References}

1 Hameed TK, Hodge WG, Buhrmann R. An inventory of information on blindness and visual impairment in Canada. Can J Ophthalmol 2001; 36: 175-185.

2 Maberley D. Discussion: an inventory of information on blindness and visual impairment in Canada. Can J Ophthalmol 2001; 36: 185-186.

3 Statistics Canada, Participation and Activity Limitation Survey 2001. www.hrdc-drhc.gc.ca/sp-ps/arb-dgra/ publications/research/2001docs/PALS.

4 The Canadian National Institute for the Blind 2001 Client Data.

5 www.statscan.com

6 Tielsch JM, Sommer A, Witt K, Katz J, Royall RM. Blindness and visual impairment in an American urban population. The Baltimore Eye Survey. Arch Ophthalmol 1990; 108: 286-290.
7 Klein R, Klein BEK, Linton KLP, De Mets DL. The Beaver Dam Eye Study: visual acuity. Ophthalmology 1991; 98: 1310-1315.

8 Attebo K, Mitchell P, Smith W. Visual acuity and causes of visual loss in Australia. The Blue Mountains Eye Study. Ophthalmology 1996; 103: 357-364.

9 Klaver CC, Wolfs RC, Vingerling JR, Hofman A, de Jong PT. Age-specific prevalence and causes of blindness and visual impairment in an older population: the Rotterdam Study. Arch Ophthalmol 1998; 116: 653-658.

10 Buch H, Vinding T, la Cour M, Appleyard M, Jensen GB, Nielsen NV. Prevalence and causes of visual impairment and blindness among 9980 Scandinavian adults. Ophthalmology 2004; 111: 53-61.

11 Buch H, Troels V, Nielsen NV. Prevalence and causes of visual impairment according to World Health Organization and United States criteria in an aged, urban Scandinavian population: The Copenhagen City Eye Study. Ophthalmology 2001; 108: 2347-2357. 